\title{
Ética em Pesquisa: Dez Anos da Resolução CNS 196/96
}

experimentação com seres humanos tem sido feita, ao longo dos séculos, com diferentes padrões de ética e qualidade, em todo o mundo. A partir da segunda metade do século passado, ocorreu um extraordinário avanço na qualidade técnica das pesquisas na área biomédica. Esse fato gerou abusos e progressivos conflitos éticos. Esse cenário foi responsável pelo surgimento de um novo campo do conhecimento humano e, posteriormente, de uma nova disciplina acadêmica, a Bioética.

O termo Bioética é um neologismo empregado pela primeira vez por Van Rensselaer Potter, bioquímico envolvido na pesquisa de câncer da Universidade de Wisconsin (EUA). Para ele seria necessário desenvolver um novo campo da ética que pudesse se direcionar para a defesa do homem, de sua sobrevivência e para uma melhora na qualidade de vida. Entretanto, foi André Hellegers, obstetra holandês que trabalhava na Georgetown University (EUA), que transpôs o termo Bioética para a medicina e as ciências biológicas, criando uma aplicação prática para esse novo campo de conhecimento teórico, denominando-o de Bioética Clínica. Apesar de a Bioética ter surgido relacionada à experimentação em seres humanos, seus conceitos foram rapidamente incorporados à prática médica assistencial, principalmente após a publicação da obra Principles of biomedical ethics, de Beauchamp e Childress, que divulgava os fundamentos da Bioética principialista: a beneficência, a não-maleficência, a autonomia e a justiça.

A Reumatologia é uma especialidade clínica que tem se caracterizado por dois paradigmas: a excelência nas pesquisas básicas e clínicas e uma prática médica eminentemente clínica, com forte apoio na relação médico-paciente. Esse aspecto de nossa prática diária coloca-nos a todo instante diante de dilemas éticos, cada vez mais freqüentes, tornando obrigatório o conhecimento por todos nós, reumatologistas, dos fundamentos da Bioética para deliberações éticas e conscientes.

Apenas recentemente a preocupação com a ética nas pesquisas tem sido discutida entre nós. A Resolução CNS 196/96 do Conselho Nacional de Saúde - Ministério da Saúde completou uma década em outubro de 2006. O extraordinário impacto qualitativo dessa Resolução nas pesquisas com seres humanos no Brasil é evidente, inclusive com reconhecimento internacional. Decorridos dez anos de sua publicação, faz-se necessário debater e refletir acerca de sua importância para a ciência brasileira, assim como uma avaliação crítica da atuação da Comissão Nacional de
Ética em Pesquisa (Conep) e dos Comitês de Ética em Pesquisa (Ceps), entidades criadas pela Resolução em tela. Vale a pena um breve histórico.

As primeiras normas reguladoras de pesquisas com seres humanos foram estabelecidas somente em 1947, após os abusos dentro e fora dos campos de concentração, durante a II Guerra Mundial. Essas normas foram estabelecidas pelo Código de Nuremberg, reconhecendo oficialmente a indisponibilidade do consentimento voluntário, a necessidade de estudos prévios em laboratório e em animais, a análise de riscos e benefícios da investigação proposta, a liberdade do sujeito da pesquisa de se retirar do estudo, a adequada qualificação do pesquisador, entre outros pontos. Merece destaque o fato de que o princípio da autonomia, um dos referenciais básicos da Bioética, foi oficialmente reconhecido nesse documento. Embora adotada nas normas de pesquisa, somente depois de muitos anos a autonomia (autodeterminação) foi incorporada à prática diária e aos códigos de Deontologia dos profissionais de saúde.

Apesar do Código de Nuremberg, os abusos continuaram a ocorrer. Beecher chama a atenção para o crescente número de pesquisas com seres humanos, nas décadas de 50 e 60 , em boa parte conduzidas de forma eticamente inadequada, sendo publicadas em revistas de alto padrão científico. O Código de Nuremberg foi revisto na $18^{\text {a }}$ Assembléia da Associação Médica Mundial, em 1964, sendo aprovada a Declaração de Helsinque, que introduzia a necessidade de revisão dos protocolos por comitês independentes. A denominação Declaração de Helsinque foi mantida nas versões posteriores realizadas em Tóquio (1975), Veneza (1983), Hong Kong (1989), Somerset West (1996) e Edinburgo (2000).

$\mathrm{Na}$ década de 80, o Council for International Organization of Medical Sciences (Cioms), juntamente com a Organização Mundial da Saúde (OMS), elaborou um documento mais detalhado, publicando as "Diretrizes Internacionais para Pesquisa Biomédica com Seres Humanos". Uma nova versão desse documento foi publicada em 1993. Finalmente, na década de 90, o Cioms publica o primeiro documento específico voltado para a pesquisa em estudos de coletividade (estudos epidemiológicos): o "International Guideline for Ethical Review of Epidemiological Studies".

No Brasil, o primeiro documento oficial visando normatizar as pesquisas em saúde foi a Resolução CNS 1, de 
junho de 1988, do Conselho Nacional de Saúde. Esse documento teve pouco impacto prático. Em 1995, foi criado um Grupo Executivo de Trabalho (GET), com o objetivo de revisar as normas de pesquisas em nosso país. Esse grupo contou com a participação de representantes de diversas áreas sociais e profissionais, como médicos, biólogos, juristas, teólogos, empresários e representantes dos usuários. O grupo foi coordenado pelo professor Dr. William Saad Hossne, a quem a comunidade científica brasileira vem prestando justos tributos por sua fundamental importância para a ciência brasileira, principalmente na área de ética em pesquisa. Finalizando seus trabalhos, o GET elaborou a Resolução CNS 196/96, publicada no DO em 10 de outubro de 1996. Esta criou os Comitês de Ética em Pesquisa (CEPs), vinculados às instituições de pesquisas, exigindo que sua composição fosse multidisciplinar (não mais que metade dos membros pertencentes a mesma profissão), incluindo, obrigatoriamente, um representante dos usuários. Criou também a Comissão Nacional de Ética em Pesquisa (Conep), órgão máximo da área, ligado ao Conselho Nacional de Saúde (CNS) - Ministério da Saúde (MS). O professor Dr. Hossne define a resolução da seguinte maneira: A resolução não é cartorial, estatutária ou código. Ela é um instrumento que obriga a análise bioética dos projetos de pesquisa. Sem ser lei, tem força legal, sem ser coercitiva, é consistente para flexibilização com responsabilidade.

Tivemos oportunidade de acompanhar a implantação dos primeiros CEPs e a enorme dificuldade operacional devido à falta de experiência de seus membros. Essa dificuldade inicial foi sendo superada lentamente e, nos últimos anos, tem ocorrido um aumento da massa crítica de pessoas competentes para essa importante função, com conseqüente crescimento qualitativo e quantitativo dos CEPs. Programas de treinamento e capacitação dos CEPs estão em pleno andamento.

Em relação à Conep, presidida competentemente pelo Dr. Hossne nessa primeira década, foram seguidos fielmente os princípios de sua criação: eqüidade, universalidade, descentralização e controle social. Ocorreu nítida evolução funcional de sua atuação, reduzindo-se os prazos dos trâmites necessários para a aprovação dos projetos de pesquisas. Resoluções conseqüentes à Resolução CNS 196/96 foram publicadas para normatizar áreas temáticas especiais, cumprindo, assim, seu princípio de descentralização progressiva.
A criação do Sistema de Informação sobre Ética em Pesquisa em Seres Humanos (Sisnep) foi um enorme avanço. Trata-se de um sistema de informação, via internet, sobre pesquisas que envolvem seres humanos, tendo acesso a essa ferramenta os cientistas que desenvolvem pesquisas, os CEPs, a Conep e a população em geral. O sistema está em pleno desenvolvimento e expansão. Os números publicados em seu site impressionam. No ano de 2004, existiam 415 CEPs e 17 mil projetos de pesquisas, envolvendo aproximadamente 680.00 sujeitos de pesquisa; cerca de 30 mil pessoas foram protegidas devido aos protocolos não aprovados para pesquisa. Atualmente existem 496 CEPs com cerca de 6 mil membros.

A produção científica brasileira na área de Reumatologia apresentou extraordinário progresso desde a fundação da Sociedade Brasileira de Reumatologia e a criação dos primeiros serviços de Reumatologia em nosso país. A evolução quantitativa e qualitativa das pesquisas, em nossos serviços ligados ou não à universidade, já é reconhecida internacionalmente. $\mathrm{O}$ aperfeiçoamento dos protocolos de investigação e a adaptação às normas de ética em pesquisa na área reumatológica são os caminhos que devem ser trilhados nos próximos anos. A participação cada vez maior de pesquisadores da área de Reumatologia nos CEPs e a inclusão de temas relacionados à ética em pesquisas em nossos eventos e publicações são outras estratégias que devem ser seguidas.

Finalmente, cumpre mencionar a fundamental importância da reflexão e discussão dos aspectos éticos em pesquisas em nossas residências de Reumatologia e pósgraduação. A Resolução 4/2003 da Comissão Nacional de Residência Médica, tornando obrigatória a abordagem teórica e prática da Bioética nos programas de residência médica, vem sendo aplicada de maneira lenta, mas gradativamente está sendo implantada em nossas residências. Essas posturas certamente contribuirão para o aprimoramento ético e científico do pesquisador na área de Reumatologia, escopo da Resolução CNS 196/96.

Um grande abraço a todos.

José Marques Filho Coordenador da Comissão de Ética e Defesa Profissional de SBR Conselheiro do Conselho Regional de Medicina do Estado de São Paulo 